\title{
Highly increased levels of active stromelysin in rheumatoid synovial fluid determined by a selective fluorogenic assay
}

\author{
Bob Beekman ${ }^{\mathrm{a}}$, Benno van $\mathrm{El}^{\mathrm{a}}$, Jan Wouter Drijfhout ${ }^{\mathrm{b}}$, H. Karel Ronday ${ }^{\mathrm{a}, \mathrm{c}}$, \\ Johan M. TeKoppele ${ }^{\mathrm{a}, *}$ \\ ${ }^{a}$ Gaubius Laboratory, TNO Prevention and Health, Department of Vascular and Connective Tissue Research, P.O. Box 2215, 2301 CE Leiden, \\ The Netherlands \\ ${ }^{\mathrm{b}}$ Department of Immunohaematology and Bloodbank, Leiden University Hospital, P.O. Box 9600, 2300 RC Leiden, The Netherlands \\ ${ }^{c}$ Department of Rheumatology, Leyenburg Hospital, Leyweg 275, $2545 \mathrm{CH}$ The Hague, The Netherlands
}

Received 22 October 1997

\begin{abstract}
Stromelysin-1 (MMP-3) is an important member of the matrix metalloproteinase family. In joint-degrading diseases like arthritis, elevated levels of MMP-3 protein are detected in synovial fluid using immunological methods. However, these methods do not discriminate between active and inactive enzyme. In the present study, a specific stromelysin activity assay was developed using the selective fluorogenic substrate TNO003 (Dabcyl-Gaba-Arg-Pro-Lys-Pro-Val-Glu $\diamond$ Nva-Trp-Arg-Glu(EDANS)-Ala-Lys-NH2, = cleavage site). For its use in biological media, cleavage of TNO003 by enzymes other than stromelysin was effectively blocked by a proteinase inhibitor cocktail. Spiking of MMP-3 to synovial fluid resulted in an MMP-3 concentration-dependent linear increase in activity. The measured MMP-3 activity was not affected by the addition of MMP-13, even in a 5-fold excess over MMP-3. Synovial fluid from rheumatoid arthritis patients demonstrated 100-fold higher levels of active stromelysin than control synovial fluids.
\end{abstract}

(C) 1997 Federation of European Biochemical Societies.

Key words: Fluorogenic substrate; Matrix metalloproteinase; MMP-3; Rheumatoid arthritis; Stromelysin; Synovial fluid

\section{Introduction}

Matrix metalloproteinases (MMP) constitute a family of enzymes involved in the degradation of the extracellular matrix in both physiological and pathophysiological turnover of tissues. The MMPs comprise four groups [1]: stromelysins (MMP-3, -10 and -11), degrading a wide range of substrates, collagenases (MMP-1, -8 and -13), which cleave interstitial collagen triple helices, gelatinases (MMP-2, and -9), mainly acting on unwound collagen and gelatin, and membrane-

\footnotetext{
*Corresponding author. Fax: (31) (71) 5181904.

E-mail: JM.teKoppele@pg.tno.nl

Abbreviations: BB94/RS47,112, [4-( $N$-hydroxyamino)-2R-isobutyl-3S(thiophen-2-ylthiomethyl)-succinyl]-L-phenylalanine- $N$-methylamide; Dabcyl, 4-((4-dimethylamino)phenylazo)benzoyl; Dnp, 2,4-dinitrophenyl; EDANS, 5-((2-aminoethyl)amino)naphthalene-1-sulfonic acid; Mca, (7-methoxycoumarin-4-yl)acetyl; MMP, matrix metalloproteinase; Nva, norvaline; RA-SF, synovial fluid of rheumatoid arthritis patients; RFU, relative fluorescence units; RP-HPLC, reversed phase-high performance liquid chromatography; SC44,463, $N$-[3-(- $N^{\prime}$-hydroxycarboxamido)2-(2-methylpropyl)propanoyl]- $O$ methyl-L-tyrosine- $N$-methylamide; SF, synovial fluid; TOF-MALDI, time-of-flight matrix-assisted laser-desorption ionization
}

type MMPs (MMP-14, $-15,-16$ and -17 ), which are able to activate proMMP-2 (reviewed in [1-3]).

Of the MMPs, in particular MMP-3 has been implicated as playing a pivotal role in joint-degrading diseases like arthritis $[4,5]$. MMP-3 synthesis by chondrocytes and synoviocytes can be induced by inflammatory mediators like interleukin-1 $[4,6]$. Highly increased levels of MMP-3 have been found in diseased arthritic cartilage [7], synovium [5,7,8], and synovial fluid [9-13]. The other stromelysins, MMP-10 and -11 , were hardly observed in joint tissues $[5,14,15]$. MMP-3 is excreted in a latent form and, once activated, can degrade a broad range of cartilaginous substrates: proteoglycans [16], collagen types IX and XI [17], and collagen type II $N$-telopeptides $[17,18]$. In addition, MMP-3 can participate in the activation of proMMP-1, $-8,-9$ and -13 [19-22], suggesting a key role for this enzyme in initiating matrix degradation.

Levels of MMP-3 in synovial fluid are mostly quantified by immunological methods; these do not discriminate between active MMP-3 ( $<5 \%$ of total), latent forms, and complexes with tissue inhibitors of metalloproteinases (TIMPs). Inasmuch as the active fraction of MMP-3 in particular is likely to reflect its matrix-degrading capacity, an activity assay seems more appropriate. Several stromelysin activity assays have been reported; they are based on macromolecular substrates like proteoglycan $[23,24]$, casein [25], and carboxylmethylated transferrin [26] or low molecular weight substrates such as substance $P$ [27]. These methods mostly involve radioactivity and/or are not specific for stromelysin [28-30]. Recently, the use of fluorogenic peptides for measuring the activity of MMPs including MMP-3 was described [31-33]. These substrates consist of a fluorophore and a light-absorbing group (quencher) attached to an amino acid sequence recognized by MMPs. Only the sequence reported by Nagase et al. [34], Mca-Arg-Pro-Lys-Pro-Val-Gly Nva-Trp-ArgLys(Dnp)- $\mathrm{NH}_{2}$ ( =cleavage site), was shown to be preferentially cleaved by MMP-3 compared to other MMPs. Application of this substrate in measurements of stromelysin activity in biological media has not been reported yet. Previously, we have shown that the fluorogenic substrate TNO211, containing the highly soluble Dabcyl/EDANS as quencher/fluorophore combination, can be conveniently used for MMP activity measurements in biological media [31]. The present study was designed to develop a specific and sensitive stromelysin activity assay for biological media, using the fluorogenic substrate Dabcyl-Gaba-Arg-Pro-Lys-Pro-Val-Glu $\$$ Nva-TrpArg-Glu(EDANS)-Gly-Lys- $\mathrm{NH}_{2}$ (TNO003), and to investigate whether stromelysin activity levels are elevated in synovial fluid from rheumatoid arthritis patients. 


\section{Materials and methods}

\subsection{Substrate TNO003 synthesis}

The fluorogenic substrate Dabcyl-Gaba-Arg-Pro-Lys-Pro-Val-Glu-

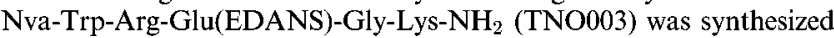
according to the method described previously [35].

\subsection{Matrix metalloproteinases}

Human recombinant proMMP-2 (EC 3.4.24.24), proMMP-3 (EC 3.4.24.17), and proMMP-13 were kindly provided by Dr. P. Mitchell (Pfizer Central Research, Groton, CT, USA). The catalytic domain of MMP-1 (19 kDa MMP-1, EC 3.4.24.7) was a gift from Dr. J. McGeehan (Glaxo-Wellcome, Research Triangle Park, NC, USA). The $19 \mathrm{kDa}$ MMP-1 has the same specific activity for small peptides as full-length MMP-1 [36,37] and was therefore assumed to be suitable for the present study. MMP-7 was supplied in its active form by Dr. P. Cannon (Roche-Syntex, Palo Alto, CA, USA), and proMMP-8 was donated by Dr. G. Murphy (Strangeways Laboratories, Cambridge, UK). Zymogens were activated by 1 mM APMA (proMMP-2, $-3,-8$, -9) or 2 mM APMA (proMMP-13) for $2 \mathrm{~h}$ (proMMP-8, -9, -13) or 16 h (proMMP-2, -3) at $4^{\circ} \mathrm{C}$ (proMMP-2) or $37^{\circ} \mathrm{C}$ (proMMP-3, 8, -9, -13 ) in buffer $\mathrm{A}$, which consisted of $50 \mathrm{mM}$ Tris (pH 7.5), $150 \mathrm{mM}$ $\mathrm{NaCl}, 5 \mathrm{mM} \mathrm{CaCl} 2,1 \mu \mathrm{M} \mathrm{ZnCl}_{2}$, and $0.01 \% \mathrm{Brij}-35$. The amounts of active enzyme were calibrated by active-site titration with TIMP-1 (MMP-1, -2, -3, -7, -8, and -13) or TIMP-2 (MMP-9) as described by others [21,38]. TIMP-1 was a gift from Dr. G. Murphy, and TIMP-2 was purchased from Boehringer Mannheim (Germany).

\subsection{Enzyme kinetics: catalytic efficiencies $\left(k_{c a t} / K_{m}\right)$}

MMP-1 (10 nM), MMP-2 (5 nM), MMP-3 (5 nM), MMP-7 $(10 \mathrm{nM})$, MMP-8 (10 nM), MMP-9 (5 nM) and MMP-13 (5 nM) were incubated with $2 \mu \mathrm{M}$ TNO003 at $25^{\circ} \mathrm{C}$ in buffer $\mathrm{A}$. All incubations described in this paper had a total volume of $180 \mu \mathrm{l}$, and were performed in black round bottom 96 well plates (Dynatech, Denkendorf, Germany). The increase in fluorescence resulting from substrate conversion was followed in a Cytofluor II (excitation filter $360 \mathrm{~nm}$, emission filter $490 \mathrm{~nm}$, from PerSeptive Biosystems). Catalytic efficiencies $\left(k_{\text {cat }} / K_{\mathrm{m}}\right)$ were calculated from the equation $[\mathrm{S}]_{\mathrm{t}} /[\mathrm{S}]_{0}=\mathrm{e}^{-k_{\mathrm{t}} \mathrm{t}}$, with $k=[\mathrm{E}]_{\text {tot }} \cdot\left(k_{\text {cat }} / K_{\mathrm{m}}\right)[33,39]$. Fluorescence after total substrate conversion $\left(\mathrm{Flu}_{\max }\right)$ is a measure for $[\mathrm{S}]_{0}$, and thus $[S]_{\mathrm{t}}$ equals $\mathrm{Flu}_{\max }-\mathrm{Flu}_{\mathrm{t}}$.

\subsection{Reversed phase-high performance liquid chromatography} (RP-HPLC)

Purification of the synthetic peptide and separation of cleavage products was performed with a Perkin-Elmer $\mathrm{C}_{18}$ Pecosphere $3 \times 3 \mathrm{C}$ column eluted with a linear acetonitrile (Rathburn, UK) gradient in $0.1 \%$ trifluoroacetic acid (Fluka, Belgium) at $1.0 \mathrm{ml} / \mathrm{min}$ delivered by a Gynkotek Model 480 pump. Samples were injected with a WISP model $710 \mathrm{~B}$ automated injector (Waters). Detection comprised absorbance at 215 or at $520 \mathrm{~nm}\left(\lambda_{\max }\right.$ of Dabcyl; Applied Biosystems, Model 759A) and fluorescence $\left(\lambda_{\mathrm{ex}}=340 \mathrm{~nm}, \lambda_{\mathrm{em}}=485 \mathrm{~nm}\right.$, Jasco 821-FP detector). Identity of the substrate and cleavage products was established by TOF-MALDI mass spectrometry [40] (Lasermat, Finnigan MAT), and amino acid analysis of collected fractions [41].

\subsection{Stromelysin activity in synovial fuid: addition of inhibitors}

Synovial fluid from a rheumatoid arthritis (RA-SF) patient was centrifuged $\left(4^{\circ} \mathrm{C}, 10000 \times g, 15 \mathrm{~min}\right)$ and the resulting cell-free supernatant was diluted 5-fold in buffer A. Stromelysin activity in SF (finally diluted 20 -fold in buffer A) was measured using $5 \mu \mathrm{M}$ TNO003 $\left(37^{\circ} \mathrm{C}\right)$ in the presence of EDTA-free Complete, a mixture of non-MMP inhibitors (final concentration: one tablet in $10 \mathrm{ml}$ buffer A; Boehringer Mannheim, Germany) to prevent conversion of TNO003 by other proteinases than MMPs. All incubations in synovial fluid contained this proteinase inhibitor cocktail.

Further improvement of assay selectivity for MMP-3 was investigated by the addition of the MMP inhibitor SC44,463 (kindly supplied by Dr. P. Mitchell, Pfizer Central Research, Groton, CT, USA), which is less potent towards MMP-3 $\left(\mathrm{IC}_{50}=30 \mathrm{nM}\right.$; determined in buffer) than towards other MMPs $\left(\mathrm{IC}_{50}=1 \mathrm{nM}\right)$. $\mathrm{IC}_{50}$ values of SC44,463 towards MMP-2, $-3,-9$, or -13 in synovial fluid were determined by the addition of SC44,463 (final concentration 0-1000 nM) together with the proteinases $(2.5 \mathrm{nM})$. Conversion of TNO003 $(5 \mu \mathrm{M})$ was determined fluorometrically $(360 / 490 \mathrm{~nm}$, Cytofluor II, Perseptive
Biosystems); and the activity measured in the absence of SC44,463 was set at $100 \%$.

\subsection{Stromelysin activity in synovial fuid}

Stromelysin activity in synovial fluid samples from patients with rheumatoid arthritis $(n=12)$ was compared with that in control synovial fluid (obtained post-mortem), from individuals without any sign of arthritis $(n=11)$. Synovial fluids were diluted 5 -fold in buffer $\mathrm{A}$ after centrifugation $\left(4^{\circ} \mathrm{C}, 10000 \times \mathrm{g}, 15 \mathrm{~min}\right)$. Stromelysin activity in $\mathrm{SF}$ (final dilution 20-fold) was measured using $5 \mu \mathrm{M}$ TNO003 in the

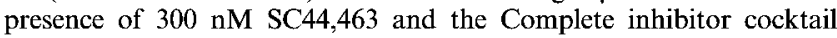
(final concentration: 1 tablet in $10 \mathrm{ml}$ buffer A). The initial velocity of substrate turnover (linear increase in fluorescence over time) was used as a measure for enzyme activity. The concentration of active stromelysin was calculated using a calibration curve of MMP-3 spiked to synovial fluid.

\section{Results}

\subsection{Substrate cleavage site}

Addition of stromelysin (MMP-3, $25 \mathrm{nM}$ ) to $4 \mu \mathrm{M}$ TNO003 (Dabcyl-Gaba-Arg-Pro-Lys-Pro-Val-Glu-Nva-Trp-Arg-Glu(EDANS)-Gly-Lys- $\mathrm{NH}_{2}$ ) resulted in a rapid increase in fluorescence indicating substrate conversion. In approximately $40 \mathrm{~min}$ the reaction was completed (Fig. 1A). As expected, HPLC analysis (Fig. 2) showed two new peaks at $215 \mathrm{~nm}$. The first peak exhibited EDANS characteristic fluorescence (CS in Fig. 2B); the second peak absorbed at $520 \mathrm{~nm}$, indicative of Dabcyl (NS in Fig. 2B). Both peaks were analyzed by amino acid analysis and by mass spectrometry and identified as H-Nva-Trp-Arg-Glu(EDANS)-Gly-Lys- $\mathrm{NH}_{2}$ and DabcylGaba-Arg-Pro-Lys-Pro-Val-Glu-OH, respectively (Fig. 2). Thus TNO003 was cleaved at the position indicated $(\bullet)$ : Dabcyl-Gaba-Arg-Pro-Lys-Pro-Val-Glu $\$$ Nva-Trp-Arg-Glu(EDANS)-Gly-Lys- $\mathrm{NH}_{2}$.

Fluorescence after total conversion (as confirmed by HPLC) was 27.5-fold higher than the basal fluorescence of TNO003. Thus fluorescence of EDANS in TNO003 was efficiently quenched by Dabcyl $(96.4 \%)$. The rate of fluorescence increase was proportional to the MMP-3 concentration (0-2 $\mathrm{nM} ; r>0.99$, Fig. 1B), and low levels of MMP-3 (down to $50 \mathrm{pM}$ ) could easily be detected by incubating for $60 \mathrm{~min}$.

\subsection{Selectivity of TNO003 towards MMPS}

Determination of the catalytic efficiencies of all MMPs available (MMP-1, -2, -3, -7, -8, -9, and -13) for TNO003
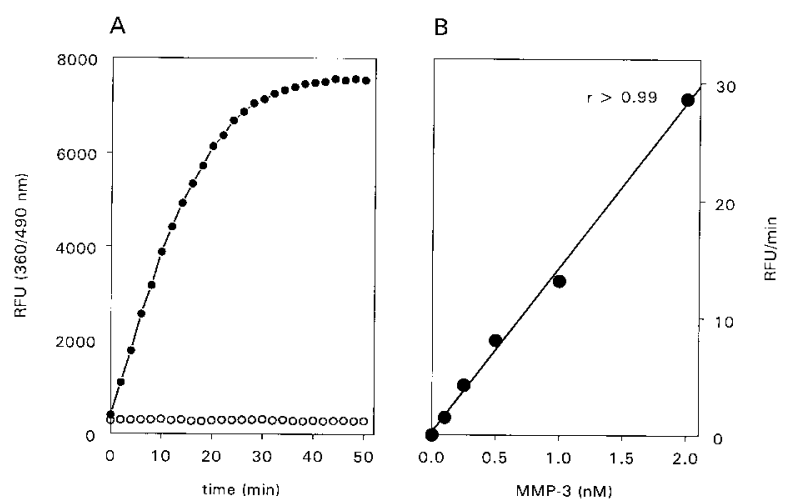

Fig. 1. A: Time curve of TNO003 $(4 \mu \mathrm{M})$ hydrolysis by $25 \mathrm{nM}$ MMP-3 at $37^{\circ} \mathrm{C}(\bullet)$. Blank: TNO003 in incubation buffer (O). B: MMP-3 activity calibration curve at $37^{\circ} \mathrm{C}$. RFU = relative fluorescence units. 
A: TNO0O3, no MMP-3

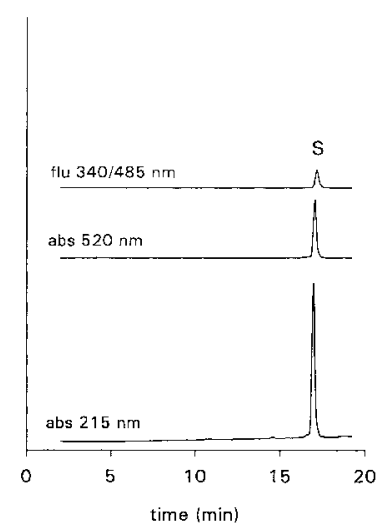

B: TNO003 + MMP-3

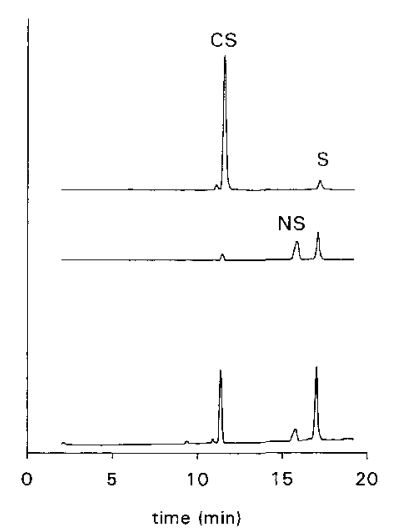

Fig. 2. HPLC analysis of TNO003 and its cleavage products generated by MMP-3. TNO003 $(15 \mu \mathrm{M})$ was incubated in the absence (A) or presence (B) of $10 \mathrm{nM} \mathrm{MMP-3}$ for $30 \mathrm{~min}$ at $22^{\circ} \mathrm{C}$. S, the parent substrate TNO003 $\left(\mathrm{MH}^{+}\right.$meas $=2065.7, \mathrm{MH}^{+}$calc $\left.=2065.4\right)$; NS, the N-terminal fragment Dabcyl-Gaba-Arg-Pro-Lys-Pro-ValGlu-OH $\left(\mathrm{MH}^{+}{ }_{\text {meas }}=1061.8, \mathrm{MH}^{+}{ }_{\text {calc }}=1060.9\right)$; $\mathrm{CS}$, the C-terminal fragment Nva-Trp-Arg-Glu(EDANS)-Ala-Lys- $\mathrm{NH}_{2} \quad\left(\mathrm{MH}^{+}{ }_{\text {meas }}=\right.$ $1020.8, \mathrm{MH}^{+}$calc $=1021.4$ ).

demonstrated that the substrate is selectively converted by MMP-3 (Fig. 3). No activity of MMP-1, -7, and -8 against TNO003 could be measured $\left(k_{\text {cat }} / K_{\mathrm{m}}<1000 \mathrm{M}^{-1} \mathrm{~s}^{-1}\right)$. MMP$2,-9$ and -13 also hydrolyzed the substrate with $k_{\text {cat }} / K_{\mathrm{m}}$ values ranging from 6000 to $14000 \mathrm{M}^{-1} \mathrm{~s}^{-1}$, but these were substantially lower than for MMP-3 $\left(29000 \mathrm{M}^{-1} \mathrm{~s}^{-1}\right)$.

\subsection{Stromelysin activity in synovial fuid: enhanced selectivity by addition of non-MMP-3 inhibitors}

In biological media, proteinases like plasmin and plasminogen activator may cleave TNO003, due to the presence of Lys$\mathrm{X}$ and $\mathrm{Arg}-\mathrm{X}$ bonds. To prevent non-MMP-related activity against TNO003, an inhibitor cocktail was added (EDTAfree Complete). Furthermore, on the basis of their $k_{\text {cat }} / K_{\mathrm{m}}$ values, MMP-2, -9 and -13 potentially disturb stromelysin activity assays in biological media for they also hydrolyze TNO003 albeit at a slower rate than MMP-3. To block this non-stromelysin activity, the synthetic MMP inhibitor SC44,463 was used. In buffer, its $\mathrm{IC}_{50}$ value for MMP-3 is approximately 30 times higher than for other MMPs $\left(\mathrm{IC}_{50} \sim 1 \mathrm{nM}\right.$ ). To investigate whether this 30 -fold difference

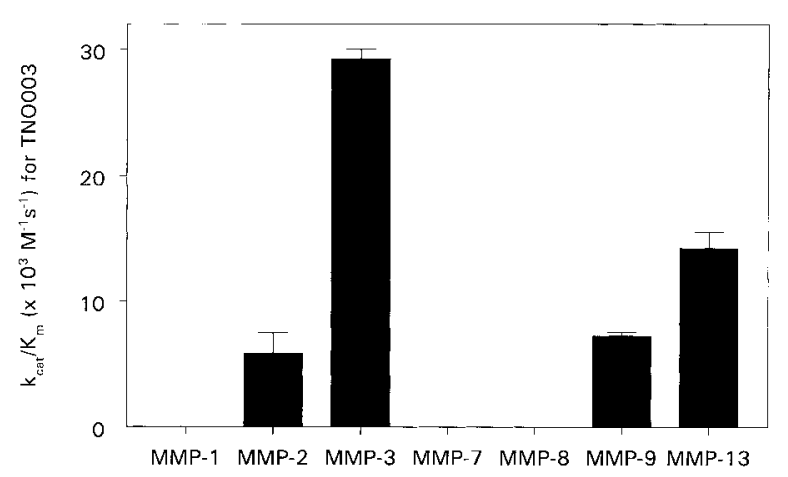

Fig. 3. Catalytic efficiencies $\left(k_{\text {cat }} / K_{\text {In }}\right)$ for conversion of TNO003 by MMPs at $25^{\circ} \mathrm{C}$. Mean \pm S.D. of three separate experiments are shown.

in $\mathrm{IC}_{50}$ value is also valid for synovial fluid, $\mathrm{IC}_{50}$ values of SC44,463 were determined in RA-SF against MMP-3, -2, -9 and -13 . These MMPs $(2.5 \mathrm{nM})$ were spiked to RA-SF, together with the non-MMP inhibitor cocktail (Complete) and SC44,463 ranging from 0 to $1000 \mathrm{nM}$. MMP-2, -9 and -13 were profoundly inhibited by $\mathrm{SC44,463}$ with $\mathrm{IC}_{50}$ values of 50-200 nM (Fig. 4A). No inhibition of MMP-3 was observed, even at the highest inhibitor concentration tested $(1 \mu \mathrm{M})$. Therefore, in all subsequent stromelysin activity assays, SC44,463 was added at $300 \mathrm{nM}$ to minimize substrate turnover by MMPs other than stromelysin.

So far, only non-activated synovial fluids were used. However, most of the stromelysin present in synovial fluid will be in the inactive pro-form. In five synovial fluids, prostromelysin was activated with the mercurial compound APMA [42] resulting in a 2-24-fold increase in activity (result of one SF sample shown in Fig. 4B). The stromelysin activity could be blocked by the potent MMP inhibitor BB94 $(10 \mu \mathrm{M})$, indicating that indeed stromelysin activity is measured.

\subsection{Effect of MMP-13 addition on measured stromelysin activity in synovial fluid}

Regarding the selective inhibition of $\mathrm{SC} 44,463$ and the lower $k_{\text {cat }} / K_{\mathrm{m}}$ of MMP-2, -9 and -13 for TNO003 than MMP-3, our stromelysin activity assays in biological media are unlikely to be disturbed by non-stromelysins. To ensure, however, that such MMPs do not interfere in this assay, a concentration
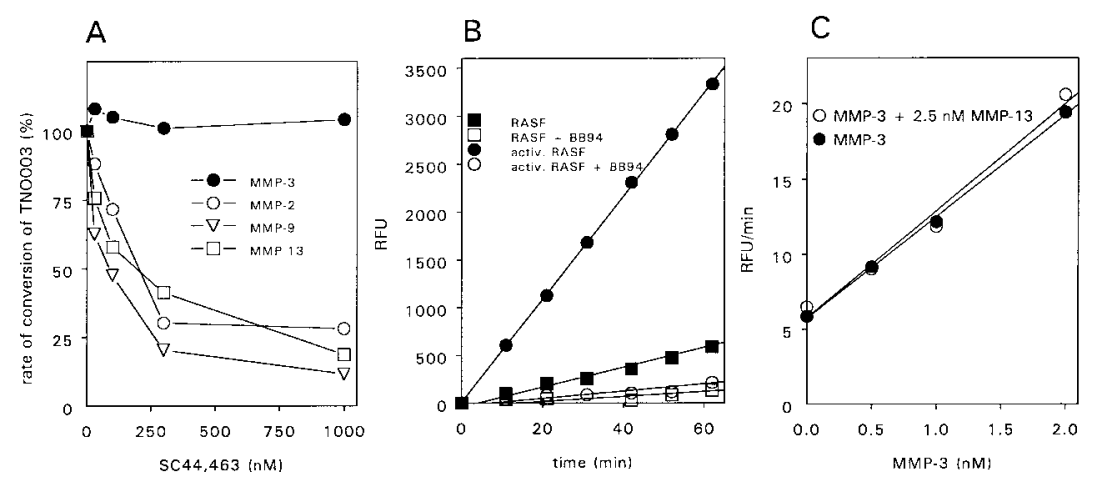

Fig. 4. A: Inhibitory capacity of the MMP inhibitor SC44,463 towards conversion of TNO003 (5 $\mu \mathrm{M})$ by MMP-2, $-3,-9$ and $-13(2.5 \mathrm{nM})$ added to synovial fluid from a rheumatoid arthritis patient. MMP activity (rate of conversion of TNO003) in the absence of SC44,463 was set at $100 \%$. B: Stromelysin activity in RA-SF; effect of activation by APMA $\left(1 \mathrm{mM}, 20 \mathrm{~h}, 37^{\circ} \mathrm{C}\right.$; activ. RA-SF $)$ and the MMP inhibitor BB94 $(10 \mu \mathrm{M})$. C: Influence of MMP-13 on the stromelysin activity measured in synovial fluid. The activity of MMP-3 (0-2 nM) added to synovial fluid from a rheumatoid arthritis patient was measured in the presence and absence of MMP-13 ( $2.5 \mathrm{nM}$; see Section 2 for details). 


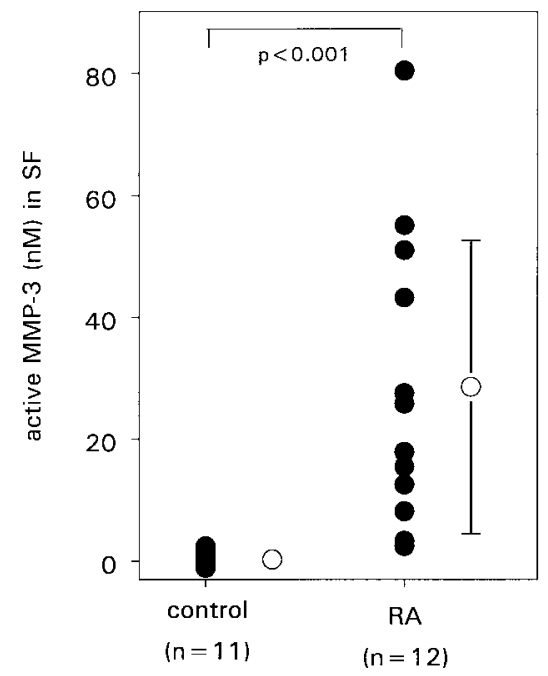

Fig. 5. Levels of active stromelysin in synovial fluid from control subjects (no sign of arthritis) and from patients suffering from rheumatoid arthritis were determined using the developed TNO003based activity assay. Closed symbols are individual data, open symbols represent the group mean \pm S.D.; see Section 2 for details. Student's $t$-test was used for statistical analysis.

range of MMP-3 (0-2 nM) was added to RA-SF and the activity against TNO003 was measured in the presence and absence of $2.5 \mathrm{nM}$ MMP-13 (Fig. 4C), which is the most disturbing enzyme regarding its $k_{\mathrm{cat}} / K_{\mathrm{m}}$ for TNO003. Under the test conditions with Complete and SC44,463 the conversion rate of TNO003 by MMP-3 was not affected by the presence of MMP-13, even when a 5-fold excess of MMP-13 (2.5 nM) over MMP-3 (0.5 nM) was used. This indicates that only stromelysin activity is determined in this TNO003-based assay format.

\subsection{Stromelysin activity in control $S F$ compared with $R A-S F$}

The activity assay with TNO003 was applied to synovial fluid obtained from rheumatoid arthritis patients (RA-SF) and from control subjects (C-SF). The concentration of active stromelysin was calculated using a calibration curve of MMP3 in synovial fluid. Virtually no stromelysin activity was observed in control SF samples $(0.3 \pm 0.5 \mathrm{nM}$ stromelysin, $n=11$ ). All synovial fluids from rheumatoid arthritis patients $(n=12)$ contained a considerable amount of active stromelysin $(28.6 \pm 24.1 \mathrm{nM})$, approximately 100 -fold higher than in synovial fluids of control subjects $(P<0.001$, Fig. 5).

\section{Discussion}

The present report describes the development of a specific assay for stromelysin activity in synovial fluid, using a selective fluorogenic substrate in combination with non-stromelysin inhibitors. The use of fluorogenic substrates together with the application in 96-well plates provides rapid and convenient measurements and allows a high sample throughput. Additionally, the assay can be applied in other biological media, involves no species-specific antibodies, and is therefore not limited to human samples.

SC44,463, an MMP inhibitor used to block MMPs other than MMP-3, showed markedly higher $\mathrm{IC}_{50}$ values $(50-200$ fold) in synovial fluid compared with those found in buffer. Most likely, this is due to a decrease in free SC44,463 in synovial fluid as a result of protein binding. This interaction with proteins may well be variable depending on physicochemical properties of the MMP inhibitor. This implies that the therapeutic efficiency of MMP inhibitors in joint-degrading diseases can differ from the inhibiting potency found in buffer. Therefore, screening of MMP inhibition by synthetic compounds in synovial fluid is likely to be more valuable than assaying in buffer since the SF data obtained better reflect the interaction between enzyme and inhibitor in vivo.

Recently, we found a 20-fold higher overall MMP activity in rheumatoid synovial fluid than in controls with the general fluorogenic MMP substrate TNO211 [31]. Here, we show that the activity of one particular MMP, stromelysin, is even 100fold higher. Thus, expression and activation of stromelysin in rheumatoid arthritis seems to be higher than that of total MMPs.

Since only active stromelysin is detected, this type of assay can be regarded as more useful than immunological methods where antibodies also recognize inhibited forms of stromelysin [9,11-13]. Thus the stromelysin activity assay provides a novel tool for investigating whether stromelysin enzyme activity is of diagnostic or prognostic value in monitoring joint destruction in arthritides.

Acknowledgements: The authors are grateful to Drs. G. Murphy and V. Knäuper (Strangeways Laboratories, Cambridge, UK), Dr. P. Mitchell (Pfizer Central Research, Groton, CT, USA), Drs. P. Cannon and R. Martin (Roche-Syntex, Palo Alto, CA, USA), and Dr. J. McGeehan (Glaxo-Wellcome, Research Triangle Park, NC, USA) for unique materials. This work was supported by a grant from Pfizer Central Research, Groton, CT, USA.

\section{References}

[1] Cawston, T.E. (1996) Pharmacol. Ther. 70, 163-182.

[2] Murphy, G. and Knäuper, V. (1997) Matrix Biol. 15, 511-518.

[3] Chandler, S., Miller, K.M., Clements, J.M., Lury, J., Corkill, D., Anthony, D.C.C., Adams, S.E. and Gearing, A.J.H. (1997) J. Neuroimmunol. 72, 155-161.

[4] Hasty, K.A., Reife, R.A., Kang, A.H. and Stuart, J.M. (1990) Arthritis Rheumatol. 33, 388-397.

[5] Hembry, R.M., Bagga, M.R., Reynolds, J.J. and Hamblen, D.L. (1995) Ann. Rheum. Dis. 54, 25-32.

[6] McNaul, K.L., Chartain, N., Lark, M., Tocci, M.J. and Hutchinson, N.I. (1990) J. Biol. Chem. 265, 17238-17245.

[7] Okada, Y., Shinmei, M. and Tanaka, O. (1992) Lab. Invest. 66, $680-690$.

[8] McCachren, S.S. (1991) Arthritis Rheumatol. 34, 1085-1092.

[9] Lohmander, L.S., Hoerrner, L.A. and Lark, M.W. (1993) Arthritis Rheumatol. $36,181-189$.

[10] Sasaki, S., Iwata, H., Ishiguro, N., Obata, K. and Miura, T. (1994) Clin. Rheumatol. 13, 228-233.

[11] Walakovits, L.A., Moore, V.L., Bhardway, N., Gallick, G.S. and Lark, M.W. (1992) Arthritis Rheumatol. 35, 35 42.

[12] Ishiguro, N., Ito, T., Obata, K.-I., Fujimoto, N. and Iwata, H. (1996) J. Rheumatol. 23, 1599-1604.

[13] Taylor, D.J., Cheung, N.T. and Dawes, P.T. (1994) Ann. Rheum. Dis. $53,768-772$.

[14] Sirum, K.L. and Brinkerhoff, C.E. (1989) Biochemistry 28, 86918698.

[15] Nawrocki, B., Polette, M., Clavel, C., Morrone, A., Eschard, J.P., Etienne, J.C. and Birembaut, P. (1994) Path. Res. Pract. $190,690-696$.

[16] Fosang, A.J., Neame, P.J., Hardingham, T.E., Murphy, G. and Hamilton, J.A. (1991) J. Biol. Chem. 266, 15579-15582.

[17] Wu, J.J., Lark, M.W., Chun, L.E. and Eyre, D.R. (1991) J. Biol. Chem. 266, 5625-5628.

[18] Böhm, B.B., Beekman, B., Drijfhout, J.W. and TeKoppele, J.M. (1996) Trans. Orth. Res. Soc. 22, 356. 
[19] Ogata, Y., Enghild, J.J. and Nagase, H.J. (1992) J. Biol. Chem. $267,3581-3584$.

[20] Suzuki, K., Enghild, J.J., Morodori, T., Salvesen, G. and Nagase, H. (1990) Biochemistry 29, 10261-10270.

[21] Knäuper, V., López-Otín, C., Smith, B., Knight, G. and Murphy, G. (1996) J. Biol. Chem. 271, 1544-1550.

[22] Knäuper, V., Wilhelm, S.M., Seperack, P.K., DeClerck, Y.A., Langley, K.E., Osthues, A. and Tschesche, H. (1993) Biochem. J. 295, 581-586.

[23] Doughty, J.R., Goldberg, R.L., Ganu, V., Melton, R.A., Hu, S.-I. and Di Pasquale, G. (1993) Agents Actions 39, C151-153.

[24] Nagase, H. and Woessner, J.F. (1980) Anal. Biochem. 107, 385392.

[25] Cawston, T.E., Galloway, W.A., Mercer, E., Murphy, G. and Reynolds, J.J. (1981) Biochem. J. 195, 159-165.

[26] Nagase, H. (1995) Methods Enzymol. 248, 449-470.

[27] Harrison, R., Teahan, J. and Stein, R. (1989) Anal. Biochem. $180,10-113$.

[28] Fosang, A.J., Neame, P.J., Last, K., Hardingham, T.E., Murphy, G. and Hamilton, J.A. (1992) J. Biol. Chem 267, 19470-19474.

[29] Manicourt, D.-H. and Lefebvre, V. (1993) Anal. Biochem. 215, $171-179$.

[30] Nakagawa, H. and Debuchi, H. (1992) Biochem. Pharmacol. 44, 1733-1777.

[31] Beekman, B., Drijfhout, J.W., Bloemhoff, W., Ronday, H.K., Tak, P.P. and TeKoppele, J.M. (1996) FEBS Lett. 390, 221-225.
[32] Knight, C.G., Willenbrock, F. and Murphy, G. (1992) FEBS Lett. 296, 263-266.

[33] Bickett, D.M., Green, M.D., Berman, J., Dezube, M., Howe, A.S., Brown, P.J., Roth, J.T. and McGeehan, G.M. (1993) Anal. Biochem. 219, 383-384.

[34] Nagase, H., Fields, C.G. and Fields, G.B. (1994) J. Biol. Chem. 269, 20952-20957.

[35] Drijfhout, J.W., Nagel, J., Beekman, B., TeKoppele, J.M. and Bloemhoff, W. (1996) in: Peptides, Chemistry, Structure and Biology (Kaumaya, P.T.P. and Hodges, R.S., Eds.), pp. 129-131, Mayflower Scientic, UK.

[36] Becherer, J.D., Howe, A., Patel, I., Wisely, B., LeVine, H, and McGeehan, G.M. (1991) J. Cell. Biochem. Suppl. 15G, 139.

[37] Murphy, G., Allan, J.G., Willenbrock, F., Cockett, M.I., O'Connell, J.P. and Docherty, A.J.P. (1992) J. Biol. Chem. 267, 96129618.

[38] Murphy, G. and Willenbrock, K. (1995) Methods Enzymol. 248, $496-528$.

[39] Wahl, R.C. (1994) Anal. Biochem. 219, 383-384.

[40] Beavis, R.C., Chaudhary, T. and Chait, B.T. (1992) Org. Mass Spectrom. 27, 156-158.

[41] Bank, R.A., Jansen, E.J., Beekman, B. and TeKoppele, J.M. (1996) Anal. Biochem. 240, 167-176.

[42] Okada, Y., Harris, E.D. and Nagase, H. (1988) Biochem. J. 254, 731-741. 